\section{Relations between Blood Glucose and Hepatic Glucose Production in Newborn Dogs}

\author{
G. HETENYI, Jun., S. VARMA, J. S. COWAN
}

British Medical fournal, 1972, 2, 625-627

\section{Summary}

No correlation was found between the concentration of glucose in blood plasma and the rate of hepatic glucose production in newborn pups aged $2 \frac{1}{2}-112$ hours. During the first few hours of life the hypoglycaemic response to insulin was small or absent. Later the response seemed exaggerated mainly owing to a slow recovery to normoglycaemia. This latter observation can be entirely accounted for by the lack of a feedback mechanism between the plasma concentration and the hepatic rate of production of glucose.

\section{Introduction}

Hypoglycaemia during the early days of life is common among many mammalian species, including man (Shelley and Neligan, 1965). In newborn dogs the blood glucose concentration is generally below that found in normal adult dogs, but occasionally high levels up to and in excess of $200 \mathrm{mg} / 100 \mathrm{ml}$ are found (Allan et al., 1966). This is in sharp contrast to the almost steady concentration of plasma glucose in adults, in whom effective feedback mechanisms regulate the rates of hepatic production and overall utilization of glucose and thus rapidly restore normoglycaemia when the concentration of glucose is raised or lowered (Hetenyi, 1971).

Glucose production increases with hypoglycaemia and decreases or stops with hyperglycaemia (de Bodo et al., 1963). The rate of utilization generally changes in the opposite direction, since glucose uptake by tissues is largely determined by the ambient glucose concentration (mass action). Thus in adults the relation between the concentration of glucose in plasma and its rates of production and utilization are part of a negative feedback mechanism with the normal glucose level as the set point. The absence of such a feedback would account for the relative persistence of low or high plasma glucose levels in neonates, the concentration settling within a broad range subject to the interplay of numerous endogenous and environmental factors.

In this study the rates of endogenous (hepatic) glucose production and the overall glucose utilization in newborn dogs were determined by a tracer method. In addition, the sensitivity to insulin (as judged by the glycaemic response) was also studied. Control experiments were carried out on the mothers a few weeks postpartum. \footnotetext{
Department of Physiology, University of Ottawa, Ottawa K1N 6N5,
Ontario, Canada

G. HETENYI, JUN., M.D., PH.D., Professor and Head of Department

S. VARMA, M.D., M.SC., Research Fellow

J. S. COWAN, M.SC., PH.D., Assistant Professor
}

\section{Material and Methods}

The studies were carried out on four litters of inbred beagle puppies (Laboratory Research Enterprises, Kalamazoo, U.S.A.) and six litters of mongrels. The ages of the animals varied from $2 \frac{1}{2}$ to 32 hours in the beagles and 3 to 112 hours in the mongrels. Their weights varied from 186 to $345 \mathrm{~g}$ and 192 to $670 \mathrm{~g}$ respectively.

The pups were anaesthetized by an intraperitoneal injection of nembutal (pentobarbitone sodium). A polyethylene catheter (PE50 Becton-Dickinson) was inserted into the left femoral vein and advanced about $3 \mathrm{~cm}$. Occasionally it was inserted into the femoral or carotid artery. Blood samples were withdrawn through the catheter. In a few pups a second catheter was placed in the jugular vein for the infusion of D-ribose or, in three cases, insulin. A glass funnel $7 \mathrm{~cm}$ in diameter was placed facing the head and a continuous flow of a mixture of $95 \% \mathrm{O}_{2}$ and $5 \%$ $\mathrm{CO}_{2}$ (carbogen) was admitted into the stem of the funnel. The animals spontaneously breathed an undetermined mixture of room air and carbogen. Despite this, owing to sluggish breathing two were anoxic, judging by the colour of the skin of the snout.

The procedures of sample collection and processing have been described (Hetenyi et al., 1961), and they were adapted to the small volumes taken $(0 \cdot 15-0.25 \mathrm{ml})$. The turnover rate, which equals the rates of hepatic glucose production and that of overall glucose utilization, was calculated by the method described by Shipley et al. (1967). Since the method yields precise results only in the presence of a steady or almost steady plasma glucose concentration pups in which the concentration of plasma glucose varied extensively or showed a definite trend during the period of observation had to be excluded.

The pups were taken from their mother two to four hours before the studies. Their temperature was held steady by a device regulated by the continuously-monitored rectal temperature. Glucose- $2{ }^{3} \mathrm{H} 50 \mu \mathrm{Ci}$ in $0.5 \mathrm{ml}$ was injected via the sampling catheter and eight blood samples were taken during the next two hours. Bovine insulin 0.12-0.15 U/kg was injected into another set of puppies, varying from two to five in number, within the same litter. Three beagles and four mongrels aged 6-24 hours, each from a different litter, received an infusion of D-ribose $4 \cdot 5-17 \mathrm{mg} / \mathrm{kg} / \mathrm{min}$. Tracer glucose was not injected into these animals.

At first glucose was determined by the glucose oxidase technique (Huggett and Nixon, 1957), but in the later studies the Beckman glucose analyser was used. Ribose was determined by the method of Roe and Rice (1948) and the radioactivity in plasma glucose by the method described by Hetenyi and Mak (1970), with a liquid scintillation spectrometer. Immunoreactive insulin concentrations were determined from $0.2 \mathrm{ml}$ of plasma according to the method of Hales and Randle (1963) and by using reagents prepared by the Radiochemical Centre, Amersham, England.

\section{Results}

The calculated rate of glucose production plotted against the concentration of glucose in the plasma in 43 pups is shown in Fig. 1. The animals with high glucose levels were anoxic as judged by the colour of their skin and their sluggish breathing. A few of the lowest values are from animals of more than 20 hours of age infused with insulin. The lack of correlation is evident and the constancy of the rate is surprising. The mongrels seemed to produce glucose at a higher rate than the inbred beagles. There was no apparent correlation with age. 


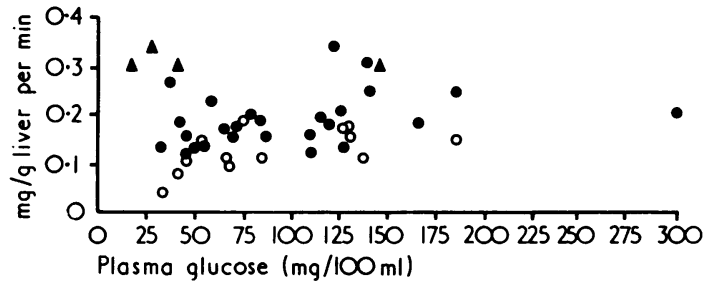

FIG. 1-Rate of hepatic glucose production $(\mathrm{mg} / \mathrm{g}$ liver $/ \mathrm{min})$ in 43 newborn dogs plotted against plasma glucose concentration $(\mathrm{mg} / 100 \mathrm{ml})$. Beagles $O$ mongrels $\Theta$, and one mongrel litter $\Delta$ with exceptionally high rates of glucose production.

Since during the period of observation the animals were near a steady state in which the rate of glucose production equals glucose utilization, the latter can be calculated by multiplying each value in Fig. 1 by the relatively constant ratio of body weight/liver weight. Thus the rate of glucose utilization also seems to be independent of the plasma concentration of glucose.

The basal concentrations of immunoreactive insulin in the plasma are given in Table I. The changes in plasma glucose after intravenous injection of $0.12 \mathrm{U}$ insulin $/ \mathrm{kg}$ in three beagles aged $2 \frac{1}{2}, 8$, and 30 hours and in their mother are shown in Fig. 2.

TABLE I-Concentration of Immunoreactive Insulin in $\mu U$ per ml of Blood Plasma of Newborn Pups (Mean \pm S.E. of Mean)

\begin{tabular}{|c|c|c|c|c|c|c|}
\hline & \multicolumn{6}{|c|}{ Age in Hours } \\
\hline & $2 \frac{1}{2}-12$ & 24 & 36 & 48 & 60 & 112 \\
\hline $\begin{array}{l}\text { Mongrels } \\
\text { Beagles }\end{array}$ & $\begin{array}{c}11.4+1 \cdot 7 \\
(13) \\
16 \cdot 6+1 \cdot 8 \\
(15)\end{array}$ & $\begin{array}{c}17 \cdot 4+4 \cdot 7 \\
(7) \\
12 \cdot 2+2 \cdot 0 \\
(6)\end{array}$ & $\begin{array}{c}10 \cdot 2+6 \cdot 7 \\
(5) \\
19 \cdot 3+4 \cdot 1 \\
(3)\end{array}$ & $\begin{array}{c}9 \cdot 3+3 \cdot 4 \\
(5)\end{array}$ & $\frac{12 \cdot 4+1 \cdot 7}{(5)}$ & $\underset{(6)}{14.9+1 \cdot 5}$ \\
\hline
\end{tabular}

Numbers of dogs are given in parentheses.

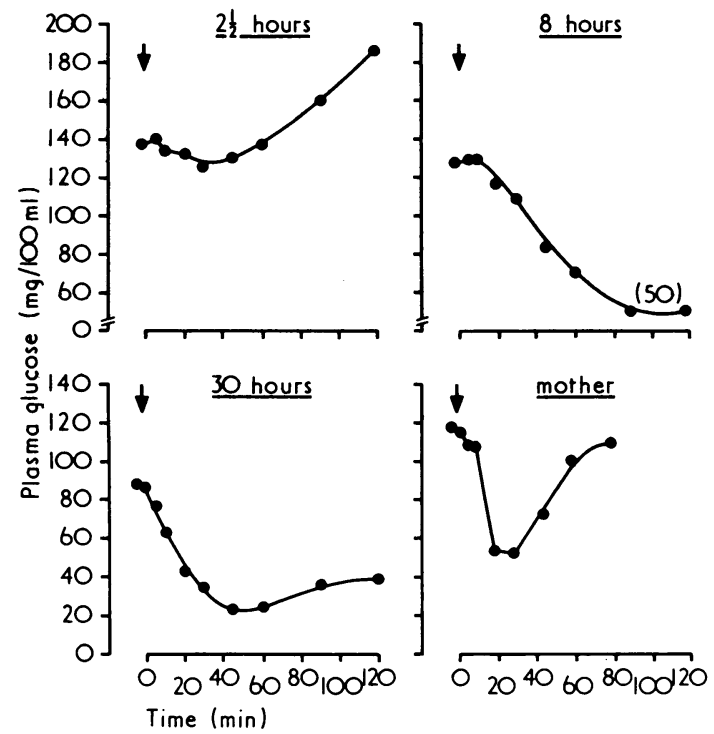

FIG. 2-Changes in plasma glucose concentration $(\mathrm{mg} / 100 \mathrm{ml})$ in newborn beagles $2 \frac{1}{2}, 8$, and 30 hours old and in their mother during a period of two hours after intravenous injection of insulin $(0 \cdot 12 \mathrm{U} / \mathrm{kg})$.

The numbers of dogs in each age group given insulin are shown in Table II. No hypoglycaemic response was observed in any pup aged less than 6 hours. The dose of insulin produced hypoglycaemia in pups aged 30 hours, but the nadir and recovery to normal level were delayed compared with those in the mother.

Ribose, which in grown dogs was shown to produce hypoglycaemia by the release of endogenous insulin in smaller amounts (Hetenyi and Ishiwata, 1968; Ishiwata et al., 1969), had no such effect in pups, though the concentration of ribose in plasma rose to $26-183 \mathrm{mg} / 100 \mathrm{ml}$ in different animals and the concentration of immunoreactive insulin in plasma rose in all
TABLE II-Number of Pups Injected with Insulin

\begin{tabular}{|c|c|c|c|c|c|c|c|c|}
\hline Age & & & & & & & Beagles & Mongrels \\
\hline $\begin{array}{l}2-7 \text { hours } \\
8-15 \text { hours } \\
16-32 \text { hours } \\
\text { 32 hours } \\
\text { Mother... }\end{array}$ & $\begin{array}{l}\ldots \\
\ldots \\
\cdots \\
\ldots\end{array}$ & $\begin{array}{l}\ldots \\
\cdots \\
\cdots \\
\cdots\end{array}$ & $\begin{array}{l}\ldots \\
\cdots \\
\cdots \\
\ldots\end{array}$ & $\begin{array}{l}\ldots \\
\cdots \\
\cdots \\
\cdots\end{array}$ & $\begin{array}{l}\ldots \\
\cdots \\
\cdots \\
\cdots\end{array}$ & $\begin{array}{l}\ldots \\
\cdots \\
\cdots\end{array}$ & $\begin{array}{l}6 \\
5 \\
4 \\
5\end{array}$ & $\begin{array}{l}2 \\
2 \\
4 \\
4 \\
1\end{array}$ \\
\hline
\end{tabular}

but one pup, the range being $36-90 \mu \mathrm{U} / \mathrm{ml}$. Thus newborn dogs are also insensitive to their own endogenous insulin.

\section{Discussion}

The apparent lack of relation between glucose production and utilization and the blood glucose concentration in newborn dogs sharply contrasts with the close relation seen in adult dogs (Hetenyi and Norwich, 1971). This suggests that glucose release and utilization are controlled by a regulatory mechanism mediated by factors other than the blood sugar level. In such a system the concentration of glucose in blood (or plasma) reflects the "metabolic clearance" of glucose-that is, the factor relating concentration and utilization (utilization/concentration $=$ metabolic clearance). The metabolic clearance has been shown to be dependent on the ambient concentration of insulin and possibly on other factors, and its variability in the newborn would hardly be surprising.

The regulator of hepatic glucose production might well be hypoxia or asphyxia. The plasma glucose concentration has been $\bar{\Phi}$ shown to increase in the mammalian neonate in either of these $\overrightarrow{0}$ states (Shelley, 1971; Edwards and Silver, 1969). The biological $N$ significance of such a regulation would be in increasing the flux of the only fuel that can be utilized by the tissues of the neonate in hypoxia. Since all our tracer experiments were carried out with a steady or almost steady glucose concentration any possible increase in glucose production during developing anoxia, when the plasma glucose level is supposedly rising, had to be disregarded. Nor did we study animals in which hyperglycaemia was induced by an infusion of glucose.

The insensitivity to insulin of the pups during the first few hours of life is not surprising. Nixon (1971) reported an insensitivity to insulin in the calf fetus at a stage of gestation at which glucose already mobilizes insulin. Our results show that insulin insensitivity persists after birth, at least in newborn dogs. After a few hours the well-known hypoglycaemic effect of insulin is seen, though recovery to normoglycaemia is much slower than in the adult. This slow recovery accords with the lack of relation between hepatic glucose release and plasma con- 을 centration. In the absence of such a correlation it is the gradual $N$ decrease of the metabolic clearance as the effect of insulin disappears which causes the glucose concentration to rise.

Since the basal immunoreactive insulin concentration in the plasma of newborn pups is about the same as in grown dogs, 0 and since there is a decreased sensitivity to insulin during early $\omega$ life, hypoglycaemia after birth cannot be caused by insulin. Nevertheless, the persistence of hypoglycaemia brought about 0 by any reason can easily be accounted for in dogs by the lack of $\Phi$ a feedback mechanism between the plasma concentration and $\stackrel{?}{+}$ rate of production of glucose up to the age of at least 5 days.

We are indebted to Mrs. Ileana Popescu and Mrs. Hiroko Nickerson for their expert technical help. The work has been $\stackrel{\mathbb{Q}}{\varrho}$ supported by generous grants received from the Medical Research 0 Colncil of Canada and the Canadian Diabetic Association.

\section{References}

Allan, D. I., Kornhauser, D., and Schwartz, R. (1966). American fournal of Diseases of Children, 12, 343

de Bodo, R. C., Steele, R., Altszuler, N., Dunn, A., and Bishop, J. S. (1963) Recent Progress in Hormone Research, 19, 445.

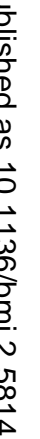

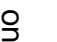


Edwards, A. V., and Silver, M. (1969). Biologia Neonatorum, 14, 1. Hales, C. N., and Randle, P. J. (1963). Lancet, 1, 200.

Hetenyi, G., jun. (1971). Acta Diabetologica Latina, 8, 213.

Hetenyi, G., jun., and Ishiwata, K. (1968). American fournal of Physiology, 214, 1333.

Hetenyi, G., jun., and Mak, G. (1970). Canadian fournal of Physiology and Pharmacology, 48, 732.

Hetenyi, G., jun., and Norwich, K. H. (1971). Federation Proceedings, 30,250 .

Hetenyi, G., jun., Wrenshall, G. A., and Best, C. H. (1961). Diabetes, 10, 301.
Huggett, A. St. N., and Nixon, D. A. (1957). Biochemical fournal, 66, 12P Ishiwata, K., Hetenyi, G., jun., and Vranic, M. (1969). Diabetes, 18, 820. Nixon, D. A. (1971). Proceedings of the International Union of Physiological Sciences, 8, 171 .

Roe, J. H., and Rice, E. W. (1948). Fournal of Biological Chemistry, 173, 507. Shelley, H. J. (1971). Physiology and Pathology in the Perinatal Period. New York, Springer.

Shelley, H. J., and Neligen, G. A. (1965). British Medical Bulletin, 22, 65.

Shipley, R. A., Chudzik, G., Gibbons, A. P., Jongedyk, K., and Brummond, O. D. (1967). American fournal of Physiology, 213, 1149.

\section{Activity Pattern of Iron-Deficient Rats}

\section{J. GLOVER, A. JACOBS}

British Medical fournal, 1972, 2, 627-628

\section{Summary}

Iron-deficient rats appear to have a decrease in total activity and a disorder of diurnal rhythm. These are reversed by the administration of iron. The results may be relevant to the symptomatology of patients with iron deficiency anaemia.

\section{Introduction}

The symptoms of iron deficiency anaemia are difficult to define in objective terms. Although most accounts of the disease describe tiredness, weakness, irritability, and other non-specific manifestations it has not been possible to substantiate these in studies based on questionnaires and simple tests of psychomotor function (Elwood et al., 1969; Elwood and Hughes, 1970).

We have used an apparatus for the continuous monitoring of rat movements to measure total daily activity and the diurnal rhythm in normal and iron-deficient rats. The results of a pilot study show that deviations from normal are found in irondeficient animals and that they are rapidly reversed by the administration of iron.

\section{Methods}

An Animex activity meter (L.K.B. Ltd.) was used to monitor total and large movements of groups of rats. Each group of three rats was placed in a standard Perspex cage which rested on six high-frequency oscillator coils. The oscillator circuit was tuned for each group of rats. The movements of the rats within the electromagnetic field produced by the apparatus resulted in an alteration of the tuning and this is registered by a scaler (Svensson and Thieme, 1969; Ogran, 1970). Two recording channels were used, one tuned for large movements and one for total movements. Small movements were found as the difference between the two.

Three groups of six male Wistar rats of similar weights were studied. In each group three rats were killed for the establishment of initial haematological criteria and three were monitored for activity. Standard haematological methods were used.

Group 1.-Normal iron status. Rats maintained on a standard diet (41B) since weaning. Activity was monitored for six days.

Department of Haematology, Welsh National School of Medicine, Cardiff

J. GLOVER, B.sC., Research Assistant

A. JACOBS, M.D., M.R.C.PATH., Professor
Ferric ammonium sulphate was given in the drinking water on days 3 and $4(28 \mathrm{mg} / 100 \mathrm{ml})$.

Group 2.-Iron deficiency anaemia. Rats maintained on an iron-free diet (McCall et al., 1962) since weaning. Activity was monitored for seven days. Ferric ammonium sulphate was given in the drinking water on days 4 and 5.

Group 3.-Mild iron deficiency anaemia. Rats maintained on an iron-deficient diet since weaning. Anaemia partially corrected by four days on normal diet given 10 days before the start of the experiment. Activity was monitored for six days. Ferric ammonium sulphate was given in the drinking water on days 3 to 6 .

Access to the animal room was strictly limited during activity measurements. Large and total movements were recorded separately for consecutive 30 -minute periods throughout the period of observation.

\section{Results}

The characteristics of each group of rats are shown in the Table. There was a considerable reduction in the total number of movements in both the mildly and severely iron-deficient rats. Large and small movements were equally affected. The effect of

Characteristics of the three Groups of Rats

\begin{tabular}{|c|c|c|c|c|c|}
\hline & & & Group 1 & Group 2 & Group 3 \\
\hline $\begin{array}{l}\text { Weight }(\mathrm{g}) \\
\text { Haemoglobin }(\mathrm{g} / 100 \mathrm{mi}) \\
\text { Packed cell volume }(\%) \\
\text { Red cell count }\left(\times 10^{\circ}\right) / 1 . \\
\text { M.C.H.C. }(\%) . . \\
\text { M.C.V. }(\mu \mathrm{m}) \\
\text { Serum iron }(\mathrm{g} / 100 \mathrm{ml}) \\
\text { Total iron binding capacity }(\mathrm{g} \\
\text { Liver non-haem (mg/100g tis } \\
\text { Total small movements in } 24\end{array}$ & 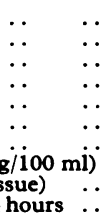 & $\begin{array}{l}\ldots \\
\cdots \\
\cdots \\
\cdots \\
\cdots \\
\cdots\end{array}$ & $\begin{array}{r}245 \cdot 0 \\
14 \cdot 6 \\
47 \cdot 0 \\
7 \cdot 9 \\
31 \cdot 0 \\
60 \cdot 0 \\
266 \cdot 0 \\
375 \cdot 0 \\
12 \cdot 0 \\
49,000\end{array}$ & $\begin{array}{r}209 \cdot 0 \\
5 \cdot 0 \\
21 \cdot 0 \\
6 \cdot 9 \\
24 \cdot 0 \\
30 \cdot 0 \\
19 \cdot 0 \\
712 \cdot 0 \\
0.9 \\
23,000\end{array}$ & $\begin{aligned} 323 \cdot 0 \\
12 \cdot 0 \\
41 \cdot 0 \\
7 \cdot 8 \\
29 \cdot 0 \\
53 \cdot 0 \\
76 \cdot 0 \\
730 \cdot 0 \\
2 \cdot 1 \\
24,000\end{aligned}$ \\
\hline
\end{tabular}

Each value is the mean of three rats. Total movements are the mean of a number of days' activity before treatment (see text).

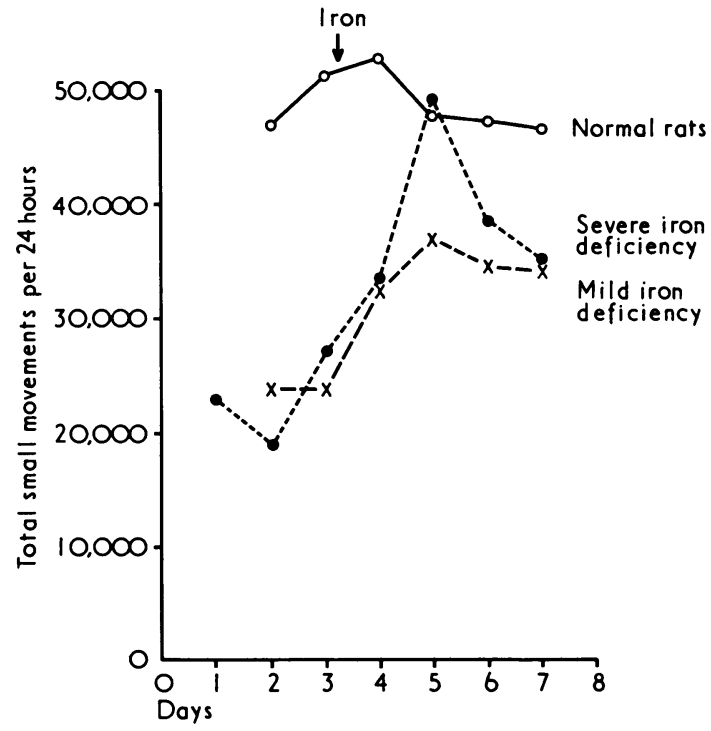

FIG. 1-Changes in activity after administration of iron in the three groups of rats. 